\title{
Carotid Endarterectomy in Awake Patient: Review Article
}

\section{๑ İbrahim Erdinç}

University of Health Sciences, İzmir Bozyaka Training and Research Hospital, Clinic of Cardiovascular Surgery, İzmir, Turkey

\begin{abstract}
Cardiac mortality and morbidity in patients undergoing carotid surgery is between $0.7 \%$ and $7.1 \%$. Although surgical techniques used in carotid surgery varies, there are differences in anesthesia techniques and the results are different. The advantages and disadvantages of anesthesia techniques are discussed in several studies and various results have been obtained. These different results involve the acquisition or loss of anesthesia technique, even if the patient group is the same. Carotid surgery under
\end{abstract}

\section{Introduction}

Carotid endarterectomy (CEA) is a surgical procedure to remove the endothelium and atherosclerotic plaque from inside the carotid artery wall. CEA may be performed under general (GA) or regional/local (LA) anaesthesiadepending on the preferences of the individual surgeon, anaesthetist and patient ${ }^{(1)}$. Stroke is the third leading cause of death and probably the most important cause of long-term disability ${ }^{(1)}$. CEA has become recognized as reliable in loco/regional anaesthesia may be thought easy. Although the complex structure of the head and neck region takes difficulty of during surgery, direct cerebral monitorization in the awake patient increases the success rate of the surgery. In this review we will explain the carotid endarterectomy management in the awake patient.

Keywords: Awake, carotid stenozis, locoregional cervical blocage, carotid endarterectomy

relieving symptoms of transient ischemic attacks and, more importantly, in the prevention of strokes due to arteriosclerotic disease at the carotid bifurcation ${ }^{(2)}$.

Eastcott performed carotid reconstruction for symptomatic internal carotid artery stenosis in 1954 under general anaesthesia for extracranial carotid obstruction ${ }^{(3)}$.

Carotid endarterectomy is a surgical procedure to remove the endothelium and atherosclerotic plaque from inside the carotid artery wall. Carotid endarterectomy

\footnotetext{
Address for Correspondence: İbrahim Erdinç, University of Health Sciences, İzmir Bozyaka Training and Research Hospital, Clinic of Cardiovascular Surgery, İzmir, Turkey

Phone: +90 5324261055 e-mail: patentheart@yahoo.com

Received: 27.02.2019 Accepted: 06.03.2019
}

Cite this article as: Erdinç İ. Carotid Endarterectomy in Awake Patient: Review Article. EJCM 2019;7(1):1-8.

DOI: 10.32596/ejcm.galenos.2019.00012 
(CEA) may be performed under general (GA) or regional/ local (LA) anaesthesiadepending on the preferences of the individual surgeon, anaesthetist and patient ${ }^{(4)}$. Tangkanakul et al. studied regional or local anaesthesia, which was preferred by most of the pioneers of CEA. However, there was concern about intraoperative cerebral ischaemia. After Wells published his series in 1963 suggesting that general anaesthesia may confer a cerebral protective effect, this technique was widely adopted ${ }^{(13)}$. Interest in loco-regional anaesthesia was subsequently revived by surgeons who believed that awake testing was the only reliable method of monitoring cerebral oxygenation. Nevertheless most surgeons continued to operate under general anaesthesia. Ultimately a generation of vascular surgeons and anaesthetists were trained to perform CEA under general anaesthesia utilising a wide variety of imperfect monitoring techniques.

\section{Surgical Technique}

CEA can be were performed either with deep or superficial regional anesthesia. Superficial cervical block was performed with the injection of $10 \mathrm{cc}$ bupivacaine $0.05 \%, 6 \mathrm{cc}$ lidocaine $2 \%$ and $4 \mathrm{cc}$ saline combination along the lateral border of the sternocleidomastoid muscle subcutaneously. Deep cervical plexus block was performed at $\mathrm{C} 2, \mathrm{C} 3$, and $\mathrm{C} 4$ level of the transverse processes of cervical vertebrae A combination of lidocaine hydrochloride and bupivacaine hydrochloride was injected after negative aspiration result for blood. A total amount of bupivacaine hydrochloride $2-3 \mathrm{mg} / \mathrm{kg}$ was allowed. Additional prilocaine hydrochloride was used subcutaneously at the incision line as infiltration anesthesia. Additional doses of prilocaine hydrochloride was injected intraoperatively if the patient complained of pain during the procedure. The allowed total dose of prilocaine was $5 \mathrm{mg} / \mathrm{kg}$. Intraoperative remifentanil $(0.025-0.05 \mathrm{mg} / \mathrm{kg} / \mathrm{min})$ maintained an adequate level of comfort, responsiveness, and cooperation. Continuous infusion of nitroglycerin was used for blood pressure control. Additional diltiazem or metoprolol was administered if needed. After de-clamping occasionally midazolam was given. Systemic heparin (100 IU/kg) was injected before clamping and was not antagonized after the procedure. A shunt was selectively used in case of neurologic deterioration at cross-clamping test at duration of 2-3 minutes. ${ }^{(16,17,20)}$

A standard incision parallel to the sternocleidomastoid muscle was performed and common carotid artery, internal carotid artery, and external carotid artery were prepared and dissected. After administrationof $5000 \mathrm{IU}$ heparin intravenously, the arteries were clamped. The consciousness and the neurologic status of the patient were evaluated with patient's response to verbal stimuli and ability to move contralateral side hand and foot for at least 2-3 minutes prior to arteriotomy. In case of neurologic disturbance, endarterectomy was performed with insertion of a shunt. The CEA with or without patchplasty was performed as usual fashion. The symptomatic otherwise more stenotic side was prioritized followed by the surgery of the contralateral side in cases with bilateral carotid disease. The optimal anesthetic tecgnique for during CEA is controversial. Advocates of regional anesthesia suggest that it may reduce the incidence of perioperative complications in addition to decreasing operative time and hospital costs. The techniques of local and regional (cervical plexus block) anesthesia for carotid surgery have been described and used since before $1962^{(5)}$. CEA surgery is commonly performed under cervical plexus blocks ${ }^{(6,7)}$. This is presumed to offer advantages over general anaesthesia in terms of monitoring neurological function during cross-clamping of the carotid artery since, in conscious patients, speech, cerebration, and motor power provide early measures of inadequate cerebral perfusion $^{(8)}$.

Some studies also claim lower shunting requirements, lower cardiovascular morbidity, and shorter hospital stay at awake patients under $\mathrm{CEA}^{(9)}$. The techniques of local and cervical-block anesthesia for carotid surgery have been described and used since before $1962^{(10)}$. During the infancy of the procedure, regional anesthesia with cervical blockage in right atrium (RA) was felt to be 
essential to the safety of the operation by preventing cerebral depression, reducing blood pressure, and allowing close observation of any neurologic changes during the operation ${ }^{(1,2)}$. There is no consensus as to which is the superior technique, but evidence from several non-randomised series suggests that LA offers considerable benefits, including a reduction in shunt placement, a reduction in mortality and major morbidity and decreased length of hospital stay ${ }^{(11)}$. Tangkanakul et al. Awake testing Hesitancy in response Gold standard Local anaesthesia Loss of consciousness Requires good communication with patient ${ }^{(4)}$. Although the studies generally reported that the patients having LA and GA were compatible in terms of age, sex and vascular risk factors, this certainly does not imply that they were similar for all important prognostic factors.

In some patients the operation may be technically more difficult under LA, e.g. in those with short, fat necks. Some patients, perhaps 10\%, 34 will also refuse to have the operation under LA $\sim$ ind some surgeons may refuse to perform the operation under LA. Pandit et al. reported that, in modern anaesthetic practice, cervical plexus blockade can be elegantly performed under ultrasound guidance with a high success rate and a low risk of procedural complications, even in patients taking dual antiplatelet therapy and in those with prior cervical surgery ${ }^{(12)}$.

Advantages of GA are:

- Control of ventilation (tight control of arterial carbon dioxide concentration) $)^{(13-17)}$

- Cerebral protection afforded by volatile anaethesia (especially during the cross-clamp) $)^{(13,18,15,19-21)}$

- Airway security (anaesthetist preference) $)^{(13,22,15,19,17)}$

- Excellent and comfortable operation conditions (especially in patients with high carotid bifurcation) ${ }^{(14,17,19-21)}$

- Prevent myocardial ischemia ${ }^{(19)}$

- Less stressful than a regional procedure ${ }^{(14,20)}$

- Prevent patients from coughing and straining ${ }^{(19)}$

- Possibility of inducing hypothermia if required ${ }^{(15)}$
Disadvantages of GA are:

- GA necessitates shunt insertion more commonly than RA techniques ${ }^{(14,15,23,27)}$

- Requires brain monitoring (stump pressure, somatosensory evoked potential, transcranial Doppler, electroencephalogram and near-infrared spectroscopy, juguler venous oxygen, cerebral oximetry $)^{(3,7,9,24,30)}$. These methods shows poor sensitivity and specificity according to awake patient, in terms of requirement for shunt placement $^{(15,24)}$

- Anaesthetic-induced circulatuar depression is associated with labile blood pressure( ${ }^{(3)}$ and necessitates greater vasopressor support (To ensure adequate cerebral perfusion pressure during carotid cross-clemping) $)^{(14,15,25,26,)}$

- Higher incidence in postoperative neurocognitive dysfunction ${ }^{(15,17)}$

Advantages of regional anesthesia are:

- Awake patient is the gold standart cerebral function monitoring ${ }^{(14,15,17,20,21)}$

- Reduce cardiac and respiratory related morbidity ${ }^{(15,16,18,20)}$

- Lower shunt insertion rate ret, $15,17,19,21,24)^{(17,19,21,24}$

- Shorten hospital stay $(14,15,17,19,21,24)$

- Lower $\operatorname{cost}^{(14,15,18,21)}$

- Improves outcomes after surgery (better postoperative analgesia, reduce blood loss, lower risk of tromboembolic events $)^{(15,18,20,22)}$

- Safer ${ }^{(14)}$

- Safe method to identify the patients at risk for crossclamp intolerance ${ }^{(1,3,12)}$

- Hemodynamic stability ${ }^{(14,17,18,21,22,24,27)}$

- Preserved cerebral autoregulation ${ }^{(14,16,18,24,25)}$

- Reduce vasopressor requirement ${ }^{(25)}$

- Reduces operative time ${ }^{(24)}$

Disadvantages of regional anesthesia are:

- Needs patient collaboration ${ }^{(14,16,23,28)}$ 
- Procedural complications (diaphragmatic and vocal cord paralysis, neural injuries, epidural, subaracnoid or intravascular injection of local anaesthetics) $)^{(15)}$

- Urgent conversion of regional anesthesia into general anesthesia $^{(15,16,26)}$

- Anxiety during the operation ${ }^{(14,16)}$

Regarding complications, superficial cardiopulmonary bypass (CPB) is associated with the common adverse effects of any nerve block such as inadvertent intravascular injection of local anesthetic and local anesthetic toxicity. In addition to these effects, deep CPB increases the occurrence of complications arising from the placement of the block, including accidental intravascular injection into the vertebral artery, subdural injection resulting in subarachnoid block, large neck hematoma, bilateral recurrentlaryngealnervepalsy, and phrenic nervepalsy ${ }^{(28-30)}$. All trials showed that blood pressure tended to increase during clamping of the carotid artery in the LA group, and in two studies there were significantly more patients with significant hypertension in the LA group during surgery (Forssell 0\% vs 36\%; Pluskwa 20\% vs $80 \%$ ). In general, hypertension seemed more common during surgery in the GA group, whilst hypotension postoperatively was more common in the LA group. There were also significantly lower odds of myocardial infarction within 30 days of surgery in patients under LA. Only a few studies assessed local haemorrhage and cranial nerve palsies. There were no significant differences between the two groups for these outcomes, the confidence intervals were wide. Only five studies reported pulmonary complications. The definition of pulmonary complication varied between different studies and included pneumonia, pulmonary emboli and prolonged intubation. These complications were very rare but there were significantly fewer pulmonary complications in the LA group ${ }^{(32,33)}$. Shunting during CEA remains controversial and, while there is no conclusive data to support or refuse the use of routine or selective shunting in carotid surgery, there is consensus that either policy is preferable to a policy of routine non-shunting ${ }^{(8,9)}$. Shunts can give rise to complications and in our opinion the finite risk of stroke associated with their use is reason enough to avoid them ${ }^{(10,11)}$. Techniques including stump pressure measurement, electroencephalography, regional cerebral blood flow measurements, near infrared spectroscopy and transcranial doppler have all been used to monitor cerebral function during GA for CEA, but none have been shown to be absolutely reliable in predicting the outcome of cross clamping. This is largely because individual patients vary in their susceptibility to reduced cerebral blood flow. The principle advantage of LA for CEA is the ability to monitor patients with direct neurological assessment and selectively shunt if they develop neurological signs ${ }^{(12,14)}$. Indeed for those surgeons who adopt a policy of selective shunting, CEA under LA is the only method capable of predicting accurately which patients need a shunt. As expected, many fewer shunts were inserted in those who had the operation under LA compared to GA $(10.8 \%$ vs $44.3 \%$, OR 0.12 , 95\% CI 0.10-0.14). However, there was significant heterogenity in the overall result ${ }^{(31-38,58)}$.

Median hospital length of stay (LOS) for GA was significantly longer compared with RA (2.0 vs 1.2 days, $\mathrm{p}<0.001)$. Patients who received GA were also more likely to be admitted to the intensive care unit ${ }^{(39)}$. The cranial nerves $(\mathrm{CN})$ can be injured during CEA by the surgical dissection, traction, electrocautery, clamp injury, or compression by a postoperative hematoma. The most commonly injured nerves are the recurrent or superior laryngeal branches of the vagus nerve (CN X-) glossopharyngeal nerve (CN IX). (Dysphagia, hoarseness, Ipsilateral vocal cord paralysis on laryngoscopy), the hypoglossal nerve (CN XI- Ipsilateral tongue deviation), the marginal mandibular branch of the facial nerve $(\mathrm{CN}$ VII- Ipsilateral facial droop, Inability to depress ipsilateral corner of lip), and the depending on the nerve that is injured, deficits vary from a minor nuisance to a severe disability that may require a feeding tube or tracheostomy, or both.

Health-related quality of life was affected in patients with Chronic Nerve Irritation (CNI) only with respect to eating and swallowing at the 2-week and 1-month 
assessment, but this finding was no longer present at 1 year. On the basis of these findings, we conclude that $\mathrm{CNI}$ is not a trivial consequence of CEA but rarely results in significant long-term disability ${ }^{(40)}$. An interesting finding of this meta-analysis is that the incidence of hypoglossal nerve injury has significantly decreased from about $8 \%$ to $2 \%$ over the last 35 years, with a mean reduction rate of $0.18 \%$ per year. Similarly, the incidence of vagus nerve injury has decreased (8\% in 1980 to $<1 \%$ nowadays), with a mean reduction rate of $0.19 \%$ per year. Although the exact reason for this decreased incidence cannot be revealed by statistical means in this meta-analysis, it is probably due to increased awareness of this kind of injury and the preventive measures taken against them. The vagus nerve appears to be the most frequently injured cranial nerve after CEA, followed by the hypoglossal nerve. Most of these injuries are transient, recovering within 6-12 months, with the recovery rate being highest in the glossopharyngeal nerve and lowest in the vagus nerve ${ }^{(41)}$. Median overall costs for GA were significantly higher than median costs for RA [medians (with interquartile ranges), $\$ 10,140$ (\$7,158$\$ 12,658)$ versus $\$ 7,122(\$ 5,072-\$ 8,511), \mathrm{p}<0.001]^{(39)}$. A meta-analysis of 41 non-randomised studies $(25,000$ CEAs) reported that CEA under locoregional anaesthesia (LRA) was associated with a $40 \%$ RRR in 30-day death/ stroke, compared with CEA under general anaesthesia (GA), as well as significant reductions in myocardial infarction (MI) and respiratory complications. Two hundred and sixty four, The General Anaesthesia Local Anaesthesia (GALA) trial (3526 patients), which is the largest RCT to date, reported no significant difference regarding perioperative death, stroke, or MI between GA (4.8\%) and LRA (4.5\%). Two hundred and sixty five, an updated Cochrane review, 266 which combined data from 14 RCTs (4596 patients), showed that CEA under LRA did not confer significant reductions in 30-day stroke (3.2\%), compared with CEA under GA (3.5\%) (42). Surgical operative time was significantly less for LA procedures, which supports the results of series ${ }^{(43)}$. CEA under LA offers several advantages over GA. These include continuous accurate neurological monitoring, decreased shunting, less intraoperative hypotension, decreased operative time and shorter hospital stays with important implications for future resource management ${ }^{(44)}$. Anesthesia time, operative time, and frequency of shunt usage were significantly greater in the general anesthesia group $(p<0.03)^{(45)}$. Hemodynamic instability during CEA is often a major concern in a patient population be set by symptomatic or occult coronary artery disease. Hypertension in particular has been implicated in perioperative neurologic complications ${ }^{(1,2)}$ and may be associated with increased use of critical care facilities and longer hospital stays ${ }^{(3,4)}$. The potential advantages of regional anesthesia for CEA include more accurate neurologic monitoring with a decreased need for intraoperative shunting and a reduction in risk associated with general anesthesia (GA) in a high-risk population. Patients who undergo CEA with CB have significantly less perioperative hemodynamic instability, suffer fewer major cardiac complications, needs for ICU admission was less frequently, and experience shorter hospital stays than the patients who undergo CEA with GA. This may result in lower costs but certainly supports consideration of the preferential use of $\mathrm{CB}$ in patients with substantial cardiac risks who would tolerate large blood pressure and heart rate (HR) shifts poorly ${ }^{(46)}$. Employing LA rather than GA for CEA has been associated with a reduction in intraoperative shunting and perioperative stroke, and the duration of hospital stay. LA appears to offer clinical and possible cost advantages over GA (regional versus general anaesthesia for CEA: Impact of change in practiceIn a unit where CEA is preferentially performed under LA, anesthesia technique failed to significantly influence outcome. Local anaesthesia enables the surgeon to assess the level of cerebral perfusion with an awake patient, gives greater assurances of cerebral protection during arterial clamping and a provides for a more relaxed and cautious endarterectomy and repair ${ }^{(47)}$. Gurer et al. reported that LA was associated with a significantly lower operation time, shunt usage rate, length of hospital stay, and rates of permanent stroke. Restenos rates, neurological events, 
and deaths were similar in the 2 groups at long-term follow-up ${ }^{(48)}$. However, the rate of shunt placement as well as operative time was lower in LA group than the general anesthesia group. Similarly, intensive care unit requirement, duration of hospital stay, and treatment costs were also lower in the local anesthesia group ${ }^{(49,50)}$.

GALA trial was a multicenter (95 centers in 24 countries), randomized controlled study comparing LA and GA during surgery in 3526 patients who had either symptomatic or asymptomatic carotid stenosis. It showed no significant difference between the two study groups at 30-day follow-up with respect to death, stroke, stroke or death, myocardial infarction, and length of hospital stay ${ }^{(51)}$. CEA in awake patient allows close follow-up of neurological functions and decision regarding necessity of intraarterial shunt during surgery. Use of intraluminal shunt and general anesthesia are routinely recommended in most studies, but unpleasant complications during placement of shunt into the internal carotid artery are well known ${ }^{(52,53)}$. Anesthesia is the one of the most controversial issues of CEA. Detailed studies have reported cervical blockage has better results concerning perioperative stroke and cardiac events, such as arrhythmia and infarction ${ }^{(54)}$. The first Cochrane review on the subject was published in 1996 and was last updated in 2013. Neither the latest Cochrane review nor the GALA trial-the single largest trial availablehave shown a statistically significant difference in outcomes between general and local anesthesia for $\mathrm{CEA}$, in respect to 30-day incidence of stroke, MI, and mortality. These studies report a trend toward lower operative mortality with local anesthetic ${ }^{(51,55)}$. Recently, increased data in favor of the locomotive have emerged compared to general anesthesia. Hussain et al., who used the Michigan Surgical Quality Collaborative database, reported that general anesthesia for CEA was associated with more than twice mortality rate compared to regional anesthesia. Leichtle et al. reported that general anesthesia is an independent risk factor for postoperative MI, especially in patients with preoperative neurological symptoms $^{(56,57)}$

\section{Conclusion}

The awake patient still has controversial parts of the carotid surgery. In many studies, as described and discussed herein, although awake patient during CEA have many advantages, in many clinics CEA is still have been performing under general anaesthesia. Perhaps the most important result of this report is, CEA being performed by local or regional techniques is that, the awake patient is the most important indicator for for direct cerebral monitoring. I performed CEA surgery in 800 patients under regional anesthesia in my institution. The patient's awake during surgery enables both the surgeon to communicate with the patient and facilitates the anesthesiologist to recognize possible complications (embolism, cross clemp intolarance). I believe that performing CEA surgery in the awake patient reduces postoperative hypotension, duration of ICU stay, postoperative complications (lung and heart) and perioperative shunt use.

\section{Acknowledgements}

I thank Fulya Y1lmaz; University of Health Sciences, İzmir Bozyaka Training and Research Hospital, Clinic of Anaesthesiology and Reanimation, İzmir, Turkey, and Murat Uğurlucan, İstanbul University, Medical Faculty, Department of Cardiovascular Surgery, İstanbul for his comments on the manuscript.

\section{Ethics}

Peer-review: Externally peer-reviewed.

Financial Disclosure: The author declared that this study received no financial support.

\section{References}

1. Bonita R. Epidemiology of stroke. Lancet 1992;339:342-4

2. Clauss RH, Sanoudas GM, Ray JF 3rd, Moallem S. Carotid endarterectomyfor cerebrovascular ischemia. Surg Gynceol Obstet 1973;136:993-1000. 
3. Eastcott HH, Pickering GW, Rob CG. Reconstruction of internal carotid artery in a patient with intermittent attacks ofhemiplegia. Lancet 1954;2:994-6

4. Tangkanakul C, Counsell CE, Warlow CP. Local versus general anaesthesia in carotid endarterectomy: a systematic review of the evidence. Eur J Vasc Endovasc Surg 1997;13.491-9.

5. Spencer FC, Eisemann B. Technique of carotid endarterectomy. Surg Gynecol Obstet 1962;115:115-7.

6. Pandit JJ, Bree S, Dillon P, Elcock D, McLaren ID, Crider B. A comparison of superficial versus combined (superficial and deep) cervical plexus block for carotid endarterectomy: a prospective, randomized study, Anesth Analg 2000;91:781-6.

7. Pandit JJ, McLaren ID, Crider B. Efficacy and safety of the superficial cervical plexus block for carotid endarterectomy. $\mathrm{Br} \mathrm{J}$ Anaesth 1999;83:970-2.

8. Andersen CA, Rich NM, Collins GJ Jr, McDonald PT. Carotid endarterectomy: regional versus general anesthesia. Am Surg 1980;46:323-7.

9. Benjamin ME, Silva MB Jr, Watt C, McCaffrey MT, Burford-Foggs A, Flinn WR. Awake patient monitoring to determine the need for shunting during carotidendarterectomy. Surgery 1993;114:673-9.

10. Spencer FC, Elsemann B. Technique of carotid endarterectomy. Surg Gynecol Obstet 1962;115:115-7.

11. Tangkanakul C, Counsell C, Warlow C. Local versus general anaesthesia for carotid endarterectomy. Cochrane Database Syst Rev 2000:CD000126.

12. Pandit JJ, Satya-Krishna R, Gration P. Superficial or deep cervical plexus block for carotid endarterectomy: a systematic review of complications. $\mathrm{Br}$ J Anaesth 2007;99:159-69.

13. Patelis N, Diakomi M, Maskanakis A, Maltezos K, Schizas D, Papaioannou M. General versus local anesthesia for carotid endarterectomy: Special considerations. Saudi J Anaesth 2018;12:612-7.

14. Kavaklı AS, Ayoğlu RU, Öztürk NK, et al. Simultaneous Bilateral Carotid Endarterectomy under Cervical Plexus Blockade. Turk J Anaesth Reanim 2015;43:367-70.

15. Zdrehuş C. Anaesthesia for carotid endarterectomy - general or locoregional? Rom J Anaesth Intensive Care 2015;22:17-24.

16. Licker M. Regional or general anaesthesia for carotid Endarterectomy Does it matter? Eur J Anaesthesiol 2016;33:241-3.

17. Ciccozzi A, Angeletti C, Guetti C, et al. Regional anaesthesia techniques for carotid surgery: the state of art. J Ultrasound 2014;17:175-83.

18. Samanta S, Samanta S, Panda N, Haldar R. A unique anesthesia approach for carotid endarterectomy: Combination of general and regional anesthesia. Saudi J Anaesth 2014;8:290-3.

19. Casutt M, Breitenmoser I, Werner L, Seelos R, Konrad C. Ultrasoundguided carotid sheath block for carotid endarterectomy: a case series of the spread of injectate. Heart Lung Vessels 2015;7:168-76.

20. Leblanc I, Chterev V, Rekik M, Boura B, Costanzo A, Bourel P, et al. Safety and efficiency of ultrasound-guided intermediate cervical plexus block for carotid surgery. Anaesth Crit Care Pain Med 2016;35:109-14.

21. Rössel T, Kerstring S, Heller AR, Koch T. Combination of high-resolution ultrasound-guided perivascular regional anesthesia of the internal carotid artery and intermediate cervical plexus block for carotid surgery. Ultrasound Med Biol 2013;39:981-6.

22. Hye RJ, Voeks JH, Malas MB, Tom ML, Longson S, Blackshear JL, et al. Anesthetic type and risk of myocardial infarction after carotid endarterectomy in the Carotid Revascularization Endarterectomy versus Stenting Trial (CREST). J Vasc Surg 2016;64:3-8.

23. Lomivorotov VV, Shmyrev VA, Moroz GB. Volatile Anesthesia for Carotid Endarterectomy: Friend or Foe for the Brain? J Cardiothorac Vasc Anesth 2018;32:1709-10.

24. Lee J, Huh U, Song S, Chung SW, Sung SM, Cho HJ. Regional Anesthesia with Dexmedetomidine Infusion: A Feasible Method for the Awake Test during Carotid Endarterectomy. Ann Vasc Dis 2016;9:295-9.

25. Tsujikawa S, Ikeshita K. Low-dose dexmedetomidine provides hemodynamics stabilization during emergence and recovery from general anesthesia in patients undergoing carotid endarterectomy: a randomized double-blind, placebo-controlled trial. J Anesth 2019.

26. Sideso E, Walton J, Handa A. General or Local Anesthesia for Carotid Endarterectomy--The "Real-World" Experience. Angiology 2011;62:609-13.

27. Cedergreen P, Swiatek F, Nielsen HB. Local anaesthesia for carotid endarterectomy Pro: protect the brain. Eur J Anaesthesiol 2016;33:236-7.

28. Stoneham MD, Stamou D, Mason J. Regional anaesthesia for carotid endarterectomy. Br J Anaesth 2015;114:372-83.

29. Singh SK. The cervical plexus: Anatomy and ultrasound guided blocks. Anaesth Pain Intensive Care 2015;19:323-32.

30. Pandit JJ, Satya-Krishna R, Gration P. Superficial or deep cervical plexus block for carotid endarterectomy: A systematic review of complications. $\mathrm{Br}$ J Anaesth 2007;99:159-69.

31. Beard J. Should all patients be shunted? If not, how can I predict which patients will require a shunt?\# In: Naylor AR (ed). Carotid artery surgery. A problem based approach. London: WB Saunders; 2000. p. 244-247.

32. Counsell C, Salinas R, Naylor R, Warlow C. Routine or selective carotid artery shunting for carotid endarterectomy (and different methods of monitoring in selective shunting). Cochrane Database Syst Rev 2000:CD000190.

33. Halsey JH Jr. Risks and benefits of shunting in carotid endarterectomy. The International Transcranial Doppler laborators. Stroke 1992;23:15837.

34. Sundt TM Jr, Ebersold MJ, Sharbrough FW, Piepgras DG, Marsh WR, Messick JM Jr. The risk-benefit ratio of intraoperative shunting during carotid endarterectomy. Ann Surg 1986;203:196-204

35. Evans WE, Hayes JP, Waltke EA, Vermilion BD. Optimal cerebral monitoring during carotid endarterectomy: neurologic response under local anesthesia. J Vasc Surg 1985;2:775-7.

36. Benjamin ME, Silva MB Jr, Watt C, McCaffrey MT, Burford-Foggs A, Flinn WR. Awake patient monitoring to determine the need for shunting during carotid endarterectomy. Surgery 1993;114:673-9.

37. Naylor AR. What evidence is there that regional anaesthesia confers any benifit over general anaesthesia? In: Naylor AR (ed). Carotid artery surgery. A problem based approach. London: WB Saunders; 2000. p. 205. 
38. Ugurlucan M, Filik ME, Caglar IM, et al. Carotid endarterectomy using a "home-constructed" shunt for patients intolerant to cross-clamping. Surg Today 2015;45:284-9.

39. Siu A, Patel J, Prentice HA, Cappuzzo JM, Hashemi H, Mukherjee D. A Cost Analysis of Regional Versus General Anesthesia for Carotid Endarterectomy. Ann Vasc Surg 2017;39:189-94

40. Hye RJ, Mackey A, Hill MD. Incidence, outcomes, and effect on quality of life of cranial nerve injury in the Carotid Revascularization Endarterectomy versus Stenting Trial. J Vasc Surg 2015;61:1208-14.

41. Kakisis JD, Antonopoulos CN, Mantas G, Moulakakis KG, Sfyroeras G, Geroulakos G. Cranial Nerve Injury After Carotid Endarterectomy: Incidence, Risk Factors, and Time Trends. Eur J Vasc Endovasc Surg 2017;53:320-35.

42. Naylor AR, Ricco JB. Response to Re: Management of Atherosclerotic Carotid and Vertebral Artery Disease: 2017 Clinical Practice Guidelines of the European Society for Vascular Surgery (ESVS). Eur J Vasc Endovasc Surg 2018;55:902.

43. Bowyer MW, Zierold D, Loftus JP, Egan JC, Inglis KJ, Halow KD. Carotid endarterectomy a comparison of regional versus general anesthesia in 500 operations. Ann Vasc Surg 2000;14:145-51.

44. McCarthy RJ, Walker R, McAteer P, Budd JS, Horrocks M. Patient and Hospital Benefits of Local Anaesthesia for Carotid Endarterectomy. Eur J Vasc Endovasc Surg 2001;22:13-8.

45. Bowyer MW, Zierold D, Loftus JP, Egan JC, Inglis KJ, Halow KD. Carotid endarterectomy: a comparison of regional versus general anesthesia in 500 operations. Ann Vasc Surg 2000;14:145-51.

46. Sternbach Y, Illig KA, Zhang R, et al. Hemodynamic benefits of regional anesthesia for carotid endarterectomy. J Vasc Surg 2002;35:333-9.

47. Mofidi R, Nimmo AF, Moores C, Murie JA, Chalmers RT. Regional versus general anaesthesia for carotid endarterectomy: impact of change in practice. Surgeon 2006;4:158-62.

48. Gürer O, Yapıcı F, Yapııı N, Özler A, Ișık Ö. Comparison between local and general anesthesia for carotid endarterectomy: early and late results. Vasc Endovascular Surg 2012;46:131-8.
49. Kalko Y, Kafali E, Aydin U, et al. Surgery of the Carotid Artery : Local anaesthesia versus general anaesthesia. Acta Chir Belg 2007;107:53-7.

50. McCarthy RJ, Walker R, McAteer P, Budd JS, Horrocks M. Patient and hospital benefits of local anaesthesia for carotid endarterectomy. Eur J Vasc Endovasc Surg 2001;22:13-8.

51. GALA Trial Collaborative Group; Lewis SC, Warlow CP. General anaesthesia versus local anaesthesia for carotid surgery (GALA): a multicentre, randomised controlled trial. Lancet 2008;372:2132-42.

52. Bonati LH, Fraedrich G; Carotid Stenting Trialists' Collaboration. Age modifies the relative risk of stenting versus endarterectomy for symptomatic carotid stenosis--a pooled analysis of EVA-3S, SPACE and ICSS. Eur J Vasc Endovasc Surg 2011;41:153-8.

53. Pennekamp CW, Immink RV, den Ruijter HM, et al. Near infrared spectroscopy to indicate selective shunt useduring carotid endarterectomy. Eur J Vasc Endovasc Surg 2013;46:397-403.

54. Chou EL, Sgroi MD, Chen SL, Kuo IJ, Kabutey NK, Fujitani RM. Influence of gender and use of regional anesthesia on carotid endarterectomy outcomes. J Vasc Surg 2016;64:9-14.

55. Vaniyapong T, Chongruksut W, Rerkasem K. Local versus general anaesthesia for carotid endarterectomy. Cochrane Database Syst Rev 2013:CD000126.

56. Hussain AS, Mullard A, Oppat WF, Nolan KD. Increased resource utilization and overall morbidity are associated with general versus regional anesthesia for carotid endarterectomy in data collected by the Michigan Surgical Quality Collaborative. J Vasc Surg 2017;66:802-9.

57. Leichtle SW, Mouawad NJ, Welch K, Lampman R, Whitehouse WM Jr, Heidenreich M. Amerikan Cerrahi Koleji Ulusal Cerrahi Kalite Geliştirme Programı'ndan genel ve bölgesel anestezi altında karotis endarterektomi sonuçları. J Vasc Surg 2012;56:81-3.

58. Ugurlucan M, Akay HT, Erdinc I, et al. Anticoagulation strategy in patients with atrial fibrillation after carotid endarterectomy. Acta Chir Belg 2018:18. 